\title{
Social Circumstances
}

National Cancer Institute

\section{Source}

National Cancer Institute. Social Circumstances. NCI Thesaurus. Code C20188.

Pertaining to the demographic and psychosocial environment in which a person lives. 